\title{
Research Article \\ Simulation of Bimetallic Bush Hot Rolling Bonding Process
}

\author{
Yaqin Tian and Qingxue Huang \\ College of Materials Science and Engineering, Taiyuan University of Science and Technology, Taiyuan 030024, China \\ Correspondence should be addressed to Yaqin Tian; tianyaqin203@163.com
}

Received 9 March 2015; Revised 28 April 2015; Accepted 29 April 2015

Academic Editor: Wei Liu

Copyright (C) 2015 Y. Tian and Q. Huang. This is an open access article distributed under the Creative Commons Attribution License, which permits unrestricted use, distribution, and reproduction in any medium, provided the original work is properly cited.

\begin{abstract}
Three-dimensional model of bimetallic bush was established including the drive roller and the core roller. The model adopted the appropriate interface assumptions. Based on the bonding properties of bimetallic bush the hot rolling process was analyzed. The optimum reduction ratio of $28 \%$ is obtained by using the finite element simulation software MARC on the assumption of the bonding conditions. The stress-strain distribution of three dimensions was research assumptions to interface deformation of rolling. At the same time, based on the numerical simulation, the minimum reduction ratio $20 \%$ is obtained by using a double metal composite bush rolling new technology from the experiment research. The simulation error is not more than $8 \%$.
\end{abstract}

\section{Introduction}

The axile bush is one of the important parts in mechanical manufacturing. Although it is not the key parts in the mechanical equipment, it occupies a large proportion in the cost of processing equipment because of special shape, processing surface, and the high metal removal rate [1]. According to preliminary estimates, it accounted for about $0.5 \%$ of the weight of the device but $2 \%$ of processing costs. Bimetallic bush is a widely applied sliding bearing with oily selflubrication characteristic nowadays [2]. It has good abrasion resistance, good condition of the less oil or intermittent oil, large load-carrying ability, long service life, and low cost. It has being replaced the traditional sleeve. For a long time, the preparation method, materials allocation and improved wear characteristics are the main research aspects for axile bush [3-6]. The composite methods of mechanics and metallurgy are important researches for the double metal composite.

The copper alloy powder is a kind of method for preparation of bimetallic bush that is sintered upon the low carbon steel plate [7] and then is rolled up. It can be used as friction reducing and wear resistant bimetallic bush. One kind of liquid metal was poured into the rotational mould and solidified for a period of time at the inner surface. Another liquid metal was poured into its inner surface and then covered the pieces of glass in the two outer layers as protection to make it evenly distributed on the inner surface under the action of centrifugal force [8]. This technique was a method of using centrifugal forming composite pipe, which can prevent the bad bonding from occurring due to the inner cooling too fast.

The molten metal was poured directly into the base material and then made the composite material by cooling, solidifying, and rolling it by the cooler roller. It was called liquid-solid rolling bonding $[9,10]$. It did not need a large amount of plastic deformation, high production efficiency, or high bonding strength, but the poor mechanical properties of products by using this technology.

Powder sintered composite method [11] was sintered two types of powder together through the pressure processing. Liquid forging [12] was the process in which the liquid metal was injected into certain metal die cavity. Then the molten or semimolten metal was solidified under the mechanical static pressure. And plastic deformation was needed in order to obtain parts in this processing. There were two processes together: the solidification under high pressure and shrink density by plastic deformation. Another composite method was the lost foam casting [13]; it was to use ordinary steel pipe as the outer pipe, then put the lost foam (made of polystyrene foam) in it, and install the gating system. A shell was formed out of the outer pipe after several dip coating and sand finishing treatments, and then they were put in the high temperature roasting furnace for calcinations. At the same time shell sintering, foam gasification, and steel pipe preheating have been finished. The antiwear alloy material 
is made after tapping furnace; that is, the wear-resisting bimetallic pipe is made of the common steel outside and antiwear alloy material inside.

To sum up, processing mould structure is not reasonable and easy to cause the product defects in most of the existing processing technology. The paper directly uses the pipe to make bimetallic bush of hot rolling composite method. The inner layer is a stainless steel tube and the outer layer is a carbon tube. Through the plastic deformation of double metal, the outer layer of carbon steel tube connects with the inner tube of stainless steel as a whole [14]. In this paper, finite element and experimental analysis of bimetallic bush hot rolling composite that needed minimum relative reduction ratio were obtained for hot rolling composite process.

\section{The Bonding Criterion of Double Metal Rolling Composite}

In the composite process as the inside and outside two kinds of metal deformation characteristics are different and they are mutually bonded under restraint [15]. At the same time as the friction resistance among the inner layer, the outer layer pipe, and the roller, the flow speed which makes the flow velocity of metal materials on the center contact section is greater than noncontact zone on both sides of the metal. But because of the internal and external layer of metal are a whole, slow moving metal tries to make the fast flowing metal slow down [16], and fast moving metal tries to make the slow flowing metal speed up. This will produce stress self-balanced mutual restraint, that is, the additional stress. The final result makes two-component deformation tend to be consistent.

The important factors of the bonding are the rolling temperature, the strain of two kinds of metal, and the additional stress variables on the bonding interface. But the interface stress is difficult to determine. The flow stress $[17,18]$ is introduced in the research of metal laminated composite superplastic deformation behavior and reference of the experience formula to determine the value. In this paper rolling temperature and two kinds of metal were known in the rolling deformation to determine the stress on the interface surface, assumed to eliminate material micro shrinkage, through calculating the ratio of the maximum additional stress and deformation resistance at the interface between the two layers of metal and then judging the adhesion of double-layer metal pipe by hot rolling composite $[19,20]$; that is,

$$
\begin{aligned}
& \frac{\operatorname{Max} \sigma_{y}}{K_{0}}=\frac{C}{\left(t_{0} / R-b\right)}+a \\
& a=0.004 r+1.8, \quad b=\frac{1}{(r+2.5)}, C=0.006 r+0.07(10<r),
\end{aligned}
$$

where $\operatorname{Max} \sigma_{y}$ is the maximum vertical stress on the interface, $K_{0}$ is the resistance of deformation, $R$ is the radius of roller $(\mathrm{mm}), r$ is reduction in pass (\%), and $t_{0}$ is the thickness of steel pipe before rolling $(\mathrm{mm})$.

The ratio of the maximum additional stress and deformation resistance on adhesive surface can be calculated through (1). There are adhesives in the adhesive interface when the ratio is greater than 1 . According to the metal tensile yield
TABLE 1: The material constants of the double layer on $1150^{\circ} \mathrm{C}$.

\begin{tabular}{lcccc}
\hline Name & $\begin{array}{c}\text { Yield limit } \\
\sigma_{s}(\mathrm{MPa})\end{array}$ & $\begin{array}{c}\text { Young's modulus } \\
E(\mathrm{MPa})\end{array}$ & $\begin{array}{c}\text { Poisson's } \\
\text { ratio } \nu\end{array}$ & $\begin{array}{c}\text { Density } \rho \\
\left(\mathrm{g} / \mathrm{cm}^{3}\right)\end{array}$ \\
\hline Q235 & 47 & $2.1 e 5$ & 0.3 & 7.8 \\
1Cr18Ni9Ti & 67 & $2.02 e 5$ & 0.3 & 7.9 \\
\hline
\end{tabular}

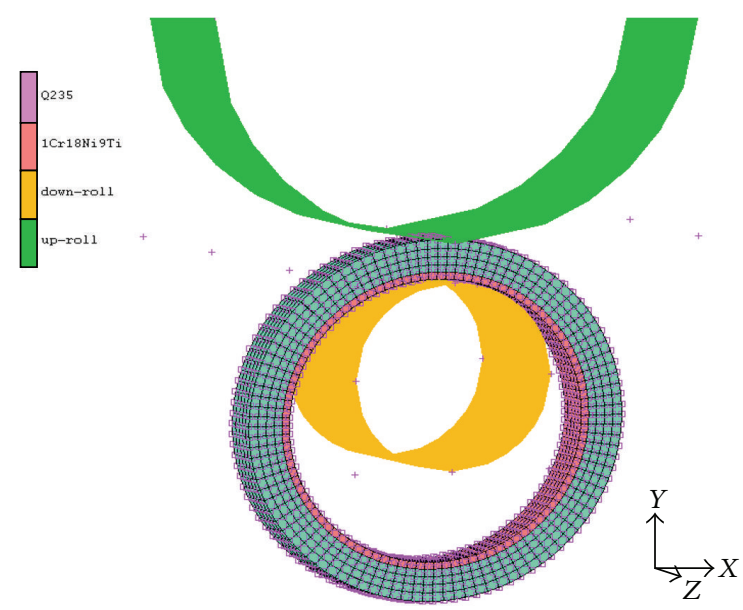

FIGURE 1: Bimetallic bush hot-rolled bonding model.

theory the flow of fast pipe achieves yield phase. At the same time, the flow slow tube is still in the stage of elastic deformation under the action which loads the instantaneous suitable external force in the composite process. The shape cannot return because the flow fast metal tube has reached the yield stage, but the slow flow metal tube can return when the external force is removed. That is, at the time of metal bonding, there is interference fit between the slow flow of metal tube and the rapid flow between the elastic deformation and the plastic deformation.

\section{Finite Element Analysis to Hot Ring Rolling Composite of Bimetallic Bush}

In this paper the material for the two kinds of material of carbon steel Q235 and stainless steel 1Cr18Ni9Ti with outer diameter $120 \mathrm{~mm}$ steel pipes is modeled by using the finite element software MARC as shown in Figure 1. The steel pipe layer thickness is $4 \mathrm{~mm}$ and the inner steel tube thickness is $1 \mathrm{~mm}$. The friction coefficient is related to the diameter of the roller, surface of roller and the shaft sleeve, the possible relative motion between the double-layer metal, the size of work piece, and other factors. The type of contact friction is coulomb friction between the roller and bimetallic bush, and the friction coefficient is 0.15 . The friction coefficient between the two deformation tubes is 0.1 [21]. The material characteristic parameters of the steel of Q235 (A3) and the austenitic stainless steel of $1 \mathrm{Cr} 18 \mathrm{Ni} 9 \mathrm{Ti}$ at $1150^{\circ} \mathrm{C}$ are shown in Table 1. The rolling feeding speed is $3 \mathrm{~mm} / \mathrm{s}$ and the drive roller speed is 3.14-5.23 rad/s. The drive roller has rotary and linear movement while the core roller has rotational movement only. The device of duo mill is asymmetrical in the structure so the 


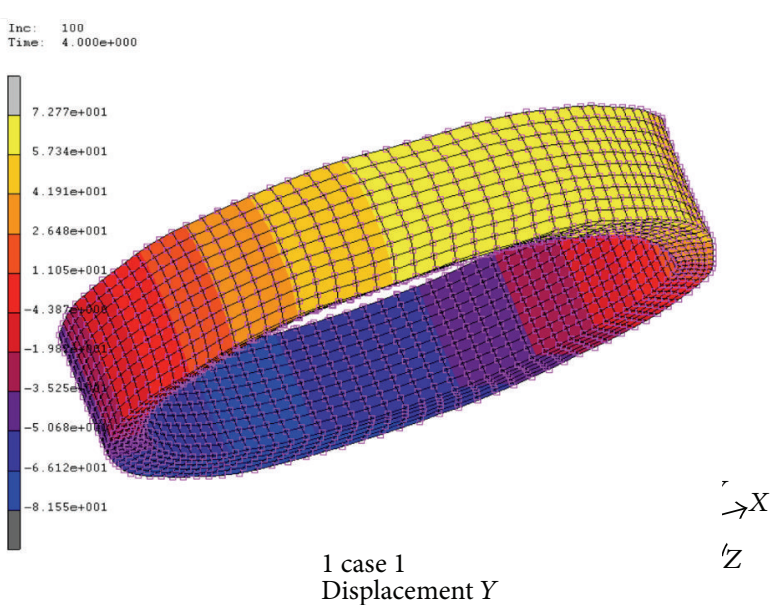

Figure 2: Bimetallic bush outer vertical displacement distribution.

analysis of bimetallic bush looks as a whole when modeling. The hexahedral mesh was selected and adaptive meshing, respectively, through the CONVERT command on the two layers of inner and outer. Because the thickness of outer layer of Q235 was larger than that of inner stainless steel, the cubic outer unit was larger than inner unit. The total calculation step is 300 . Rolling steady state process model is shown in Figure 2.

The model adopts the following treatment: in the process of establishing three-dimensional model, there are two different element types and contact hypothesis between the outer layer and inner metal because its relative distance is a minimum. There is the same distribution element along the rolling direction on the two contact surfaces; that is, the stress and strain on the node of contact surface are coordination in the deformation process. The method is good for finite element calculation procedures. The stress and strain value of nodes on the interface is desirable. The results of analysis are calculated from the reduction ratio $40 \%$ decreasing in turn 5\% until a critical value. The minimum time step length and step loading method are adopted. This makes the displacement of workpiece each step move very little. The drive roller is moved to vertical displacement on the beginning. If there is enough rolling reduction, workpiece is driven entirely by roller rotating friction to the rolling end. In the loading process the displacement of each substep is moving small. It can get the corresponding numerical of the steady state rolling process for the bonding judgment.

\section{Postprocessing of FEM Results}

The deformation resistances of outer metal Q235 are smaller than the inner layer metal $1 \mathrm{Cr} 18 \mathrm{Ni} 9 \mathrm{Ti}$. Therefore the outer layer metal is the first yield. The key research of hot rolling process is to get the minimum rolling reduction ratio under the good bonding.

4.1. Strain Distribution. The vertical strain and equivalent strain distribution are shown in Figure 3. It can be seen that the deformation degree of workpiece in the reduction amount is $40 \%$. From the strain diagram, it can be seen that the strain is gradually increasing from the inner to the outer surface. The deformation resistance of Q235 steel is relatively small, so the elongation of Q235 steel is bigger than the stainless steel on the rolling area at the same rolling reduction. When the reduction ratio is decreased, at the same time, the vertical strain and the equivalent strain are decreased too. This trend is consistent with the actual situation.

The deformation is not uniform near the bonding surface between inner and outer layer. The deformation is uneven with the difference reduction because of the difference of yield limit and plastic hardening for different material (carbon steel and stainless steel). The stress state of two kinds of materials is different from the roll gap constraint. If the relative slide between the inner layer and the outer layer is not considered or when two materials have bonded together, it will generate an additional stress field because of the consistency of flow state between two layers. So the residual stress is produced in bimetallic bush after bonding. It is effect of shape control for axile bush.

4.2. Stress Distribution. According to (1), bonding of bimetallic bush can be judged according to the vertical compressive stress between two layers. From the contact stress of two-layer metal the deformation of bimetallic bush concentrates on mainly in the range of the contact surface of roller and sleeve. The maximum deformation lies in the outer sleeve and the minimum deformation in the center of thickness direction. The distribution of stress and variation of the sleeve's surface can be obtained: the compressive stress is almost symmetrical distribution and the maximum stress stays on the rolling beginning of contact surface.

The vertical stress curves are drawn from selected node on rolling area through the CONVERT command of MARC. Stainless steel 1Cr18Ni9Ti stress distribution in Figure 4 and the reduction ratio is $40 \%, 35 \%, 30 \%$, and $25 \%$ of the stress distribution curve as shown in Figure 5.

Take nodes on the edge as follows: 1460, 1520, 1580, 1640, 1700,1760 , and 1820 .

The vertical direction of the corresponding compressive stress and its unit is $\mathrm{MPa}$. The average value is

$$
\begin{aligned}
& \left|\sigma_{22}^{40 \%}\right|=\frac{1}{7}\left(\left|\sigma_{22}^{5480}\right|+\left|\sigma_{22}^{5540}\right|+\left|\sigma_{22}^{5600}\right|+\left|\sigma_{22}^{5660}\right|\right. \\
& \left.+\left|\sigma_{22}^{5720}\right|+\left|\sigma_{22}^{5780}\right|+\left|\sigma_{22}^{5840}\right|\right)=\frac{1}{7}(145.705 \\
& +164.619+237.9224+253.74+316.911 \\
& +153.8637+183.62)=208.05 \mathrm{MPa}>67 \mathrm{MPa}
\end{aligned}
$$

Therefore, the vertical compressive stress of stainless steel $1 \mathrm{Cr} 18 \mathrm{Ni} 9 \mathrm{Ti}$ on contact surface has been greater than its deformation resistance at $1150^{\circ} \mathrm{C}$. So according to the above criterion it can be concluded that metal pipe has already bonding.

As above, the vertical stress average values of $148.94 \mathrm{MPa}$, 94.79 $\mathrm{MPa}$, and $46.51 \mathrm{MPa}$ were calculated, when the reduction ratio is $35 \%, 30 \%$, and $25 \%$. We found that 


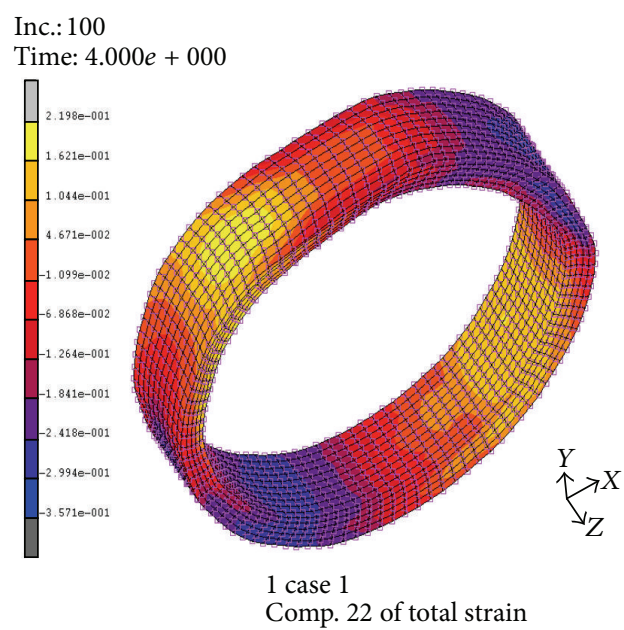

(a) Vertical strain distribution on $40 \%$ reduction rate
Inc.: 100

Time: $4.000 e+000$

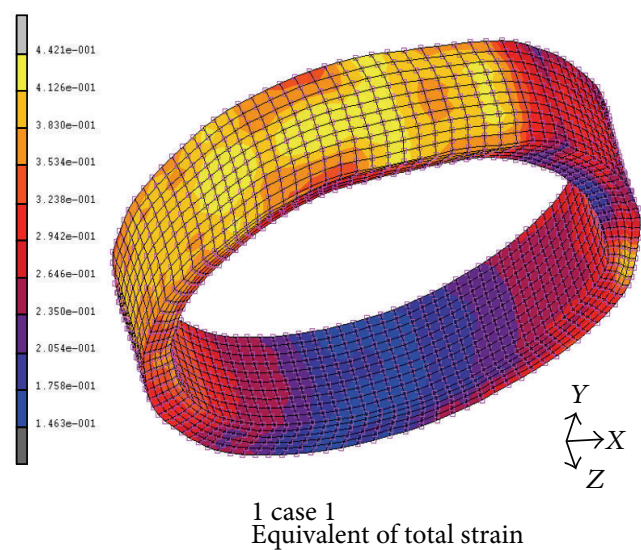

(b) Equivalent strain distribution on $40 \%$ reduction rate

FIGURE 3: Vertical strain and equivalent strain distribution in deformation zone.

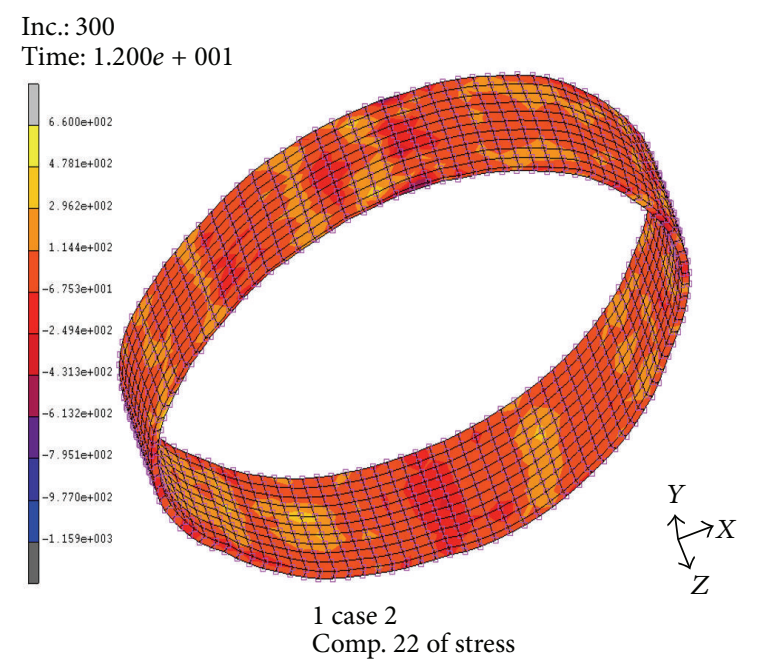

FIGURE 4: Vertical stress distribution of 1Cr18Ni9Ti stainless steel in rolling process.

$46.51 \mathrm{Mpa}<67 \mathrm{MPa}$ on the reduction ratio is $25 \%$. Because the deformation resistance of stainless steel is $67 \mathrm{MPa}$, there is no bonding on reduction ratio of $25 \%$.

The deformation resistance of the stainless steel is $67 \mathrm{MPa}$ between $94.79 \mathrm{MPa}$ and $46.51 \mathrm{MPa}$. So the suitable reduction ratio should be in $25 \% \sim 30 \%$. For more detail, the reduction ratio of $28 \%$ is analyzed. The vertical compressive stress distribution at reduction ratio of $28 \%$ is shown in Figure 6.

The compressive stress on vertical direction at $28 \%$ reduction ratio is calculated as follows:

$$
\begin{gathered}
\left|\sigma_{22}^{30 \%}\right|=\frac{1}{7}\left(\left|\sigma_{22}^{1460}\right|+\left|\sigma_{22}^{1520}\right|+\left|\sigma_{22}^{1580}\right|+\left|\sigma_{22}^{1640}\right|\right. \\
\left.+\left|\sigma_{22}^{1700}\right|+\left|\sigma_{22}^{1760}\right|+\left|\sigma_{22}^{1820}\right|\right)=\frac{1}{7}(21.137
\end{gathered}
$$

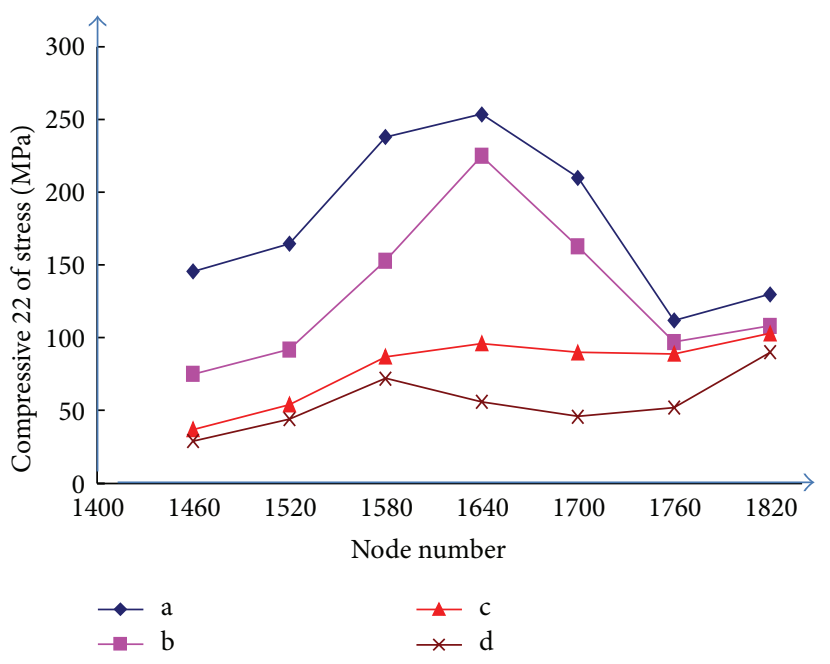

FIGURE 5: Stress distribution at the reduction ratio of $a=40 \%, b=$ $35 \%, c=30 \%$, and $d=25 \%$.

$$
\begin{aligned}
& +55.03457+120.1909+70.283+80.2203 \\
& +58.4061+80.083)=69.34 \mathrm{MPa}>67 \mathrm{MPa}
\end{aligned}
$$

At this time, the pressure stress at the vertical direction of stainless steel composite pipe on the interface is just greater than the resistance of stainless steel deformation. Q235 steel pipe and the $1 \mathrm{Cr} 18 \mathrm{Ni} 9 \mathrm{Ti}$ stainless steel pipe are good bonding just now.

Therefore, when the minimum reduction ratio is $28 \%$, double metal (1Cr18Ni9Ti/Q235) is bonding in hot rolling. If it decreases, it will no longer be bonding. 


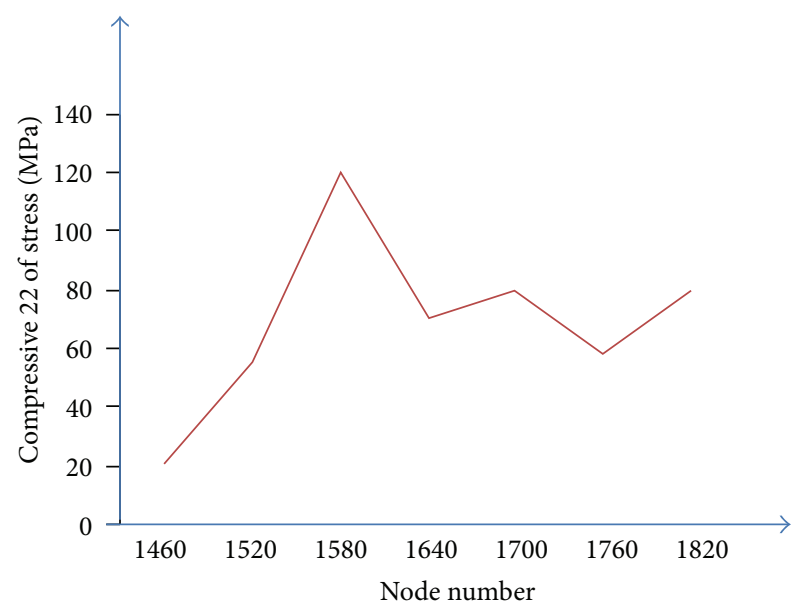

FIGURE 6: Distribution of vertical stress of interfacial edge node at $28 \%$ reduction ratio.

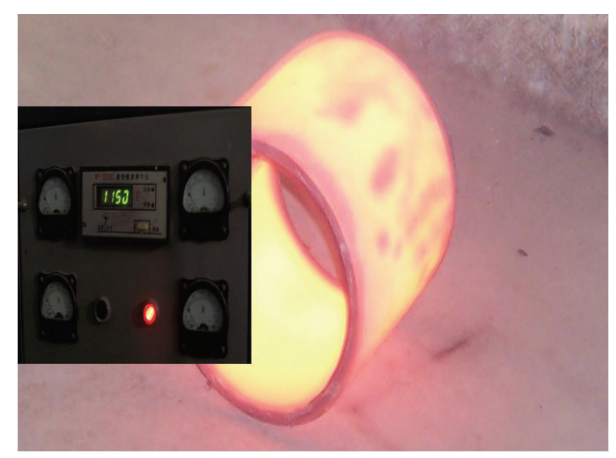

FIgURE 7: To be rolling bimetallic bush at $1150^{\circ} \mathrm{C}$.

\section{Experimental Study}

We are prepared to do the experiment in order to study the bonding characteristics of the metal axile bush. The sample is the outer diameter $120 \mathrm{~mm}$ with thickness of $4 \mathrm{~mm}$ steel Q235 as outer layer and the stainless steel of $1 \mathrm{~mm}$ thickness as inner layer. The experimental steps are as follows: (1) carbon steel tube and stainless steel tube are assembled after cleaning the surface; (2) two-layer tube is to reach the preliminary mechanical binding after expanding, bulging, and eliminating interlayer gap; (3) double metal tube is installed in the roller and then blooming, which makes the storage discharge the gas between the interlayers, and then the inner layer stainless steel tube is flanged edge; (4) double metal tube is heated at $1150^{\circ} \mathrm{C}$, and after one hour the temperature reached the experimental values as shown in Figure 7; (5) bimetallic bush is rolled at the speed of $4 \mathrm{rad} / \mathrm{s}$, the first turn under reduction of $1.2 \mathrm{~mm}$ and $1.5 \mathrm{~mm}$; (6) uninstall the bimetallic bush and then peel test in order to verify the bonding.

Based on the finite element calculation results, experiments are carried out on the reduction ratios of $1.5 \mathrm{~mm}$, $1.2 \mathrm{~mm}, 1.0 \mathrm{~mm}$, and $0.7 \mathrm{~mm}$. Double metal layers can be bound on the first three reduction conditions, but there are separate layers on the reduction ratio of $0.75 \mathrm{~mm}$. At this time the two layers of metal are still in the mechanical bonding

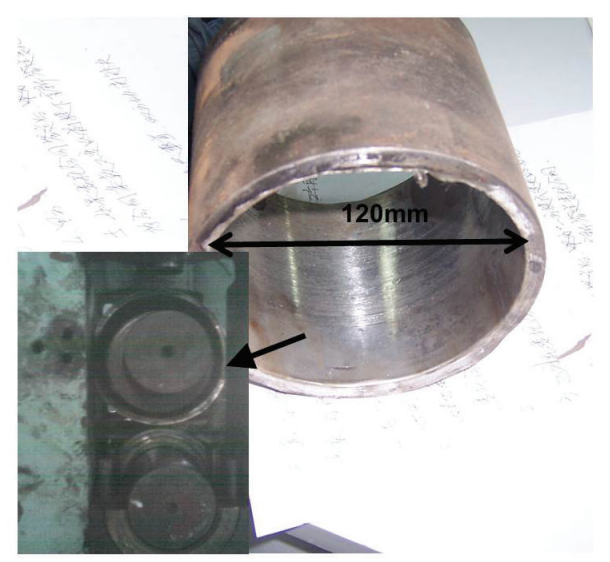

Figure 8: Amount under the pressure caused by uneven edge burr.

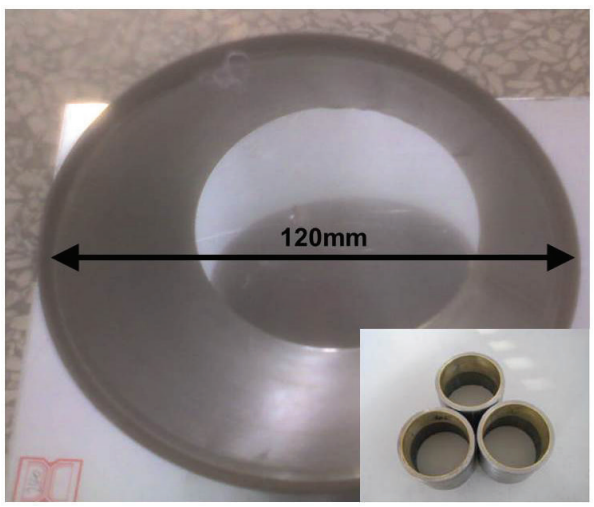

FiguRE 9: Bimetallic bush after repaired.

state because the delamination between two layers of metal is obvious. It has yet been to achieve metallurgical bonding. To set reduction by manually tightening pressure bolt before rolling, so the bimetallic bush is not uneven load pressure on radial. It is rotation and movement on the roller. It leads to the mutual abrasion between the edge of bimetallic bush and the roller. Bush appeared as edge burr as shown in Figure 8. After many experiments at the rolling reduction of $1.0 \mathrm{~mm}$ at speed of $4 \mathrm{rad} / \mathrm{s}$, good results are shown in Figure 9 by experiment. The minimum reduction ratio at the experiment is $20 \%$.

\section{Discussion}

Depression ratio is adjusted by the housing adjustment screw to observe the effect of rolling in the rolling experiments of bimetallic bush because of the test limits. Experimental data and simulation results have somewhat error. On the one hand it is due to the characteristics of two-metal-layer rolling with the inhomogeneity of deformation which is not at the same time. So pull-down phenomenon and the complex stress state occurred.

On the other hand, it is due to the fact that there is different friction between the friction of roller and bimetal and the friction of general mechanics. In the deformation process of double metal rolling, the shape and size change 
along the rolling. The new contact surface generated between roller and metal. The friction process becomes complicated and the friction coefficient is changed.

In addition, there are often iron oxide in the primary and regeneration on the surface of bimetal in the heating rolling. Thus iron oxide has a great influence on the friction. It plays a certain degree of lubrication under the high temperature. This situation is not considered in the finite element analysis. The same friction coefficient is used in the simulation. The friction load can be simplified which is the main reason for error between the finite element analysis and the experimental results. At the same time it assumed as rigid body roller in the finite element analysis. But from the main analysis of the bimetal it can produce large deformation. There is a certain elastic deformation of rolls although there are deformations of upper and lower roll though it is very small in the actual production. And these factors led to a reduction in a small error.

\section{Conclusions}

(1) Ensure the minimum reduction ratio of $28 \%$ is obtained by using the finite element simulation software MARC on the assumption of the bonding conditions.

(2) Based on the numerical simulation, the minimum experimental reduction ratio $20 \%$ is obtained by using a double metal composite bush rolling new technology by tightening the pressure bolt. The simulation error is not more than $8 \%$.

\section{Conflict of Interests}

The authors declare that there is no conflict of interests regarding the publication of this paper.

\section{Acknowledgments}

This work was financially supported by Doctoral Project of the Taiyuan University of Science and Technology of Shanxi Province in China (Grant no. 20122003) and 973 Program in China (Grant no. 2011CB612204).

\section{References}

[1] Z. Xiao, "Types of bimetallic bearing materials for bearing bush and combination technology," New Technology \& New Process, vol. 8, pp. 63-66, 2008.

[2] E. L. Shvedkov, "Self-lubricating bearing materials-a survey," Soviet Powder Metallurgy and Metal Ceramics, vol. 22, no. 6, pp. 454-467, 1983.

[3] O. A. Katrus and V. M. Kryachek, "Experience with the manufacture of bimetallic frictional elements by the rolling technique," Poroshkovaya Metallurgiva, vol. 3, no. 183, pp. 8-11, 1978.

[4] X. Xu, Z. Yu, and Y. Chen, "Fracture and wear failure of a locomotive turbocharger-bearing sleeve," Journal of Failure Analysis and Prevention, vol. 11, no. 6, pp. 672-678, 2011.
[5] A. A. Loza, "Effect of bearing-sleeve material and type of lubrication on power parameters of pulping machines," Chemical and Petroleum Engineering, vol. 20, no. 4, pp. 175-177, 1984.

[6] N. M. Ene and F. Dimofte, "The influence of the sleeve elastic deformations on the wave bearing performance in heavy loaded transmissions," in Power Transmissions, vol. 13 of Mechanisms and Machine Science, pp. 299-308, Springer, 2013.

[7] M.-H. Jiang, Z.-F. Gu, X.-Y. Liu, J. Cheng, and X.-J. Zhou, "Preparation of $\mathrm{Al} / \mathrm{Tb} 0.3 \mathrm{Dy} 0.7 \mathrm{Fe} 1.95$ magnetostrictive composites by powder sintering process," Journal of Aeronautical Materials, vol. 29, no. 3, pp. 13-16, 2009.

[8] T. P. D. Rajan, E. Jayakumar, and B. C. Pai, "Developments in solidification processing of functionally graded aluminium alloys and composites by centrifugal casting technique," Transactions of the Indian Institute of Metals, vol. 65, no. 6, pp. 531-537, 2012.

[9] Y. Watanabe, S. Watanabe, and K. Matsuura, "Nickel-aluminides/steel clad pipe fabricated by reactive centrifugal casting method from liquid aluminum and solid nickel," Metallurgical and Materials Transactions A: Physical Metallurgy and Materials Science, vol. 35, no. 5, pp. 1517-1524, 2004.

[10] X.-G. Li, B.-M. Li, G.-M. Xu, and J.-Z. Cui, "Microstructure of $\mathrm{Al}-\mathrm{Sn}-\mathrm{Si}-\mathrm{Pb} /$ steel bimetal strip produced by liquid-solid rolling-bonding," Journal of Northeastern University (Natural science), vol. 23, no. 12, pp. 1177-1180, 2002.

[11] B.-Y. Li, L.-J. Rong, Y.-Y. Li, and V. E. Gjunter, "An investigation of the synthesis of Ti-50 At. pct Ni alloys through combustion synthesis and conventional powder sintering," Metallurgical and Materials Transactions A, vol. 31, no. 7, pp. 1867-1871, 2000.

[12] S.-B. Bin, S.-M. Xing, L.-M. Tian, N. Zhao, and L. Li, "Influence of technical parameters on strength and ductility of AlSi9Cu3 alloys in squeeze casting," Transactions of Nonferrous Metals Society of China, vol. 23, no. 4, pp. 977-982, 2013.

[13] F. Li, H. Shen, and B. Liu, "Approach for mold filling simulation in lost foam casting," Acta Metallurgica Sinica, vol. 39, no. 7, p. 686, 2003.

[14] M. Eizadjou, A. K. Talachi, H. D. Manesh, H. S. Shahabi, and K. Janghorban, "Investigation of structure and mechanical properties of multi-layered $\mathrm{Al} / \mathrm{Cu}$ composite produced by accumulative roll bonding (ARB) process," Composites Science and Technology, vol. 68, no. 9, pp. 2003-2009, 2008.

[15] G. Zu, M. Zhang, and G. Yao, "Study on bonding mechanism of foaming precursor prepared by roll-bonding technology," Rare Metal Materials and Engineering, vol. 37, no. 3, pp. 485-489, 2008.

[16] C. V. Gemmiti and R. E. Guldberg, "Shear stress magnitude and duration modulates matrix composition and tensile mechanical properties in engineered cartilaginous tissue," Biotechnology and Bioengineering, vol. 104, no. 4, pp. 809-820, 2009.

[17] C. Sun, J. Luan, G. Liu, R. Li, and Q. Zhang, "Predicted constitutive modeling of hot deformation for AZ31 magnesium alloy," Acta Metallurgica Sinica, vol. 48, no. 7, pp. 853-860, 2012.

[18] L. Wu, Q. Ma, C. Zhang, S. Guan, and X. Liu, "Flow stress and constitutive model of AZ70 Mg-alloy at elevated temperatures," Rare Metal Materials and Engineering, vol. 37, no. 1, pp. 54-57, 2008.

[19] J.-F. Lin, F. Li, and J.-F. Zhang, "A new approach to investigate real flow stress in micro-extrusion," Transactions of Nonferrous Metals Society of China, vol. 22, no. 2, pp. s232-s238, 2012. 
[20] M.-Q. Li, F.-L. Jiang, H. Zhang, and L.-X. Li, "Deformation rule of steel/aluminum metal-laminate material during hot roll bonding," The Chinese Journal of Nonferrous Metals, vol. 19, no. 4, pp. 644-648, 2009.

[21] H. Wang, Metallurgical Mechanical Design Manual, China Science and Technology Culture Publishing House, Beijing, China, 5th edition, 2006. 

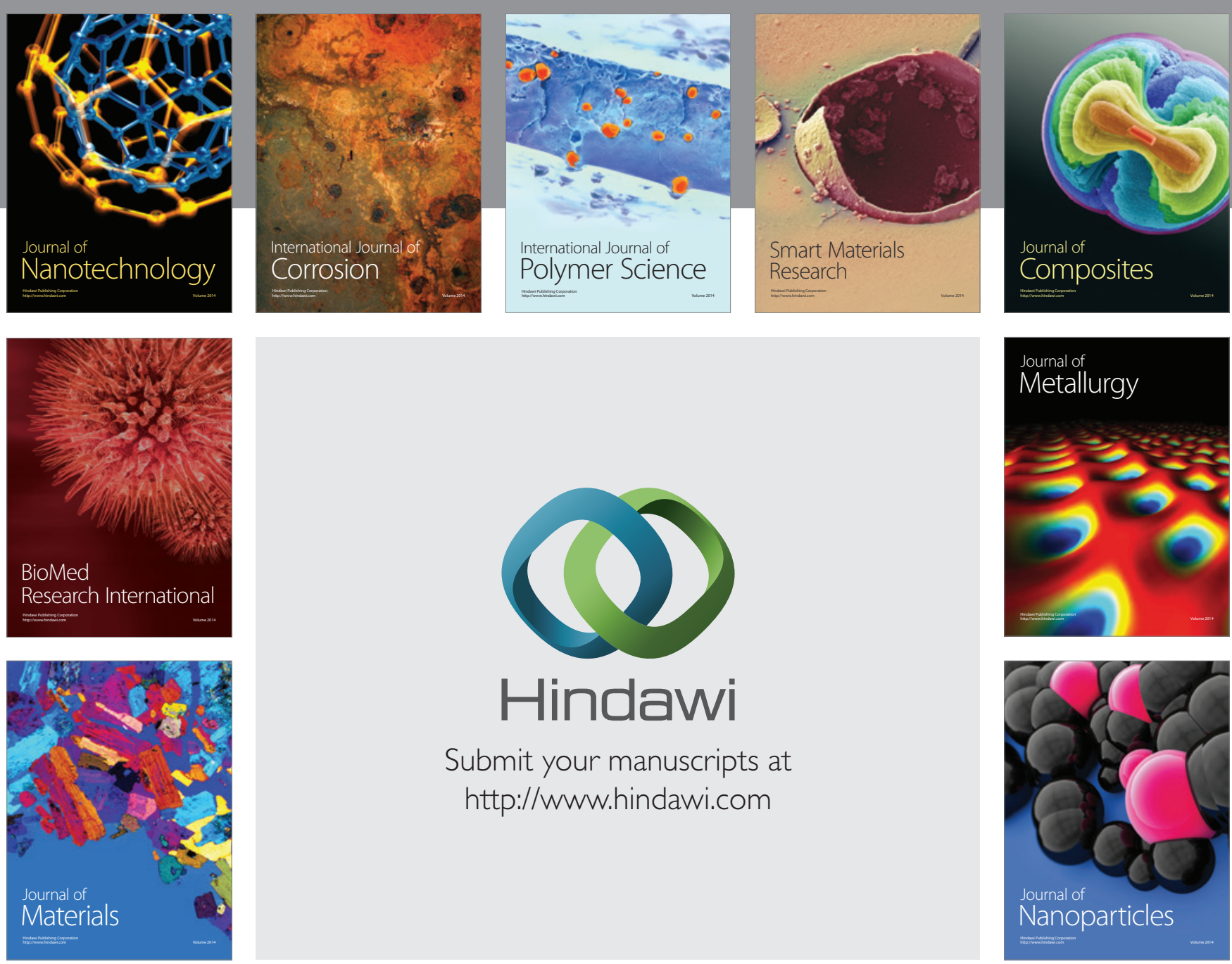

Submit your manuscripts at http://www.hindawi.com
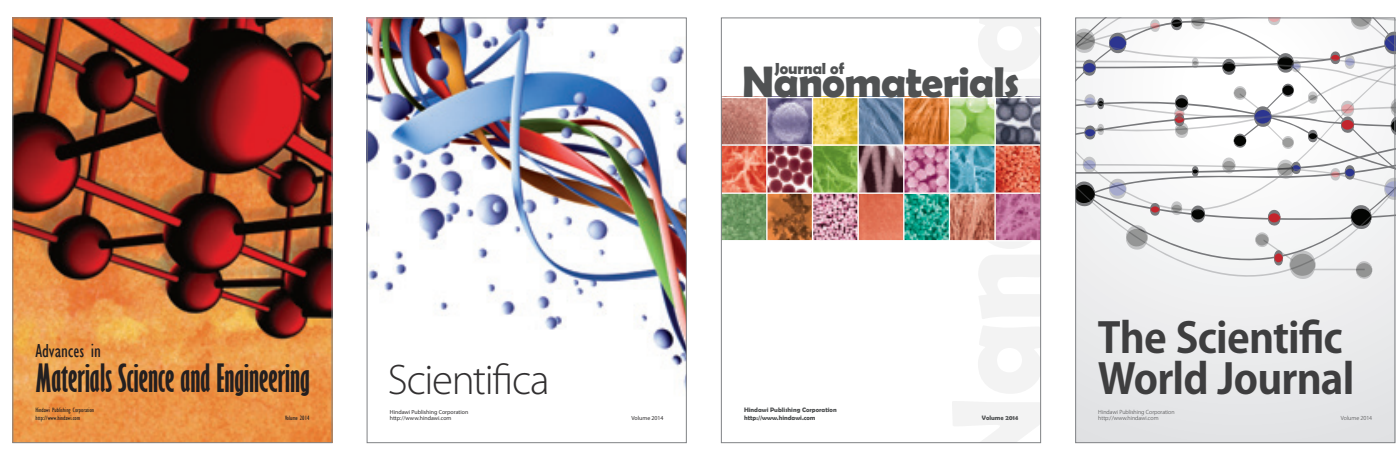

\section{The Scientific World Journal}
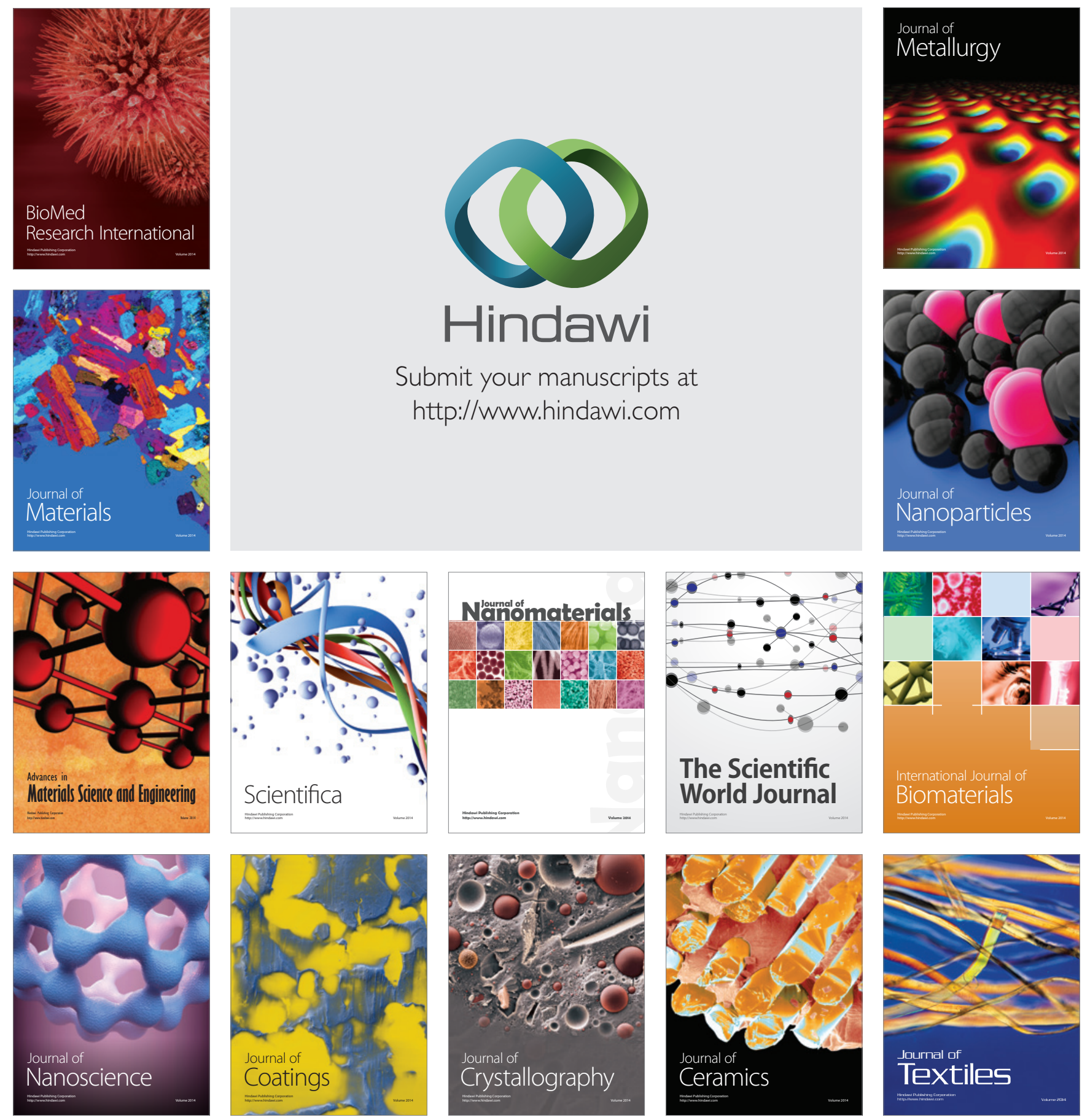